\title{
Fundaciones teóricas: Bajtín y Lotman. Una revisión en perspectiva
}

Pampa Arán

Universidad Nacional de Córdoba

\author{
No existe nada muerto de una manera absoluta: cada sentido tendrá su \\ fiesta de resurrección. Problema del Gran Tiempo \\ Bajtin \\ (...) el sistema posee una memoria de los estados precedentes en un po- \\ tencial "presentimiento" del futuro. \\ Lotman
}

Las polémicas acerca de la cientificidad del conocimiento en las ciencias humanas y sociales fueron siempre persistentes y los cambios operados en los consensos disciplinarios han alcanzado niveles críticos en las últimas décadas. Ello me ha sugerido la posibilidad de poner en intersección dos matrices teóricas de filiación dialéctica, la de Bajtín y la de Lotman, desde una tercera mirada que practique una interferencia, como acción destinada a producir un efecto de arrastre y superposición interpretativa, en lo que el semiólogo Verón llama "condiciones de reconocimiento" operación que resulta de una acción discursiva sobre textos que llamamos "fundadores" (1998: pp. 30-31). ${ }^{1}$ Sabido es, como señala Mancuso, que:

Los primeros manifiestos de Tartu (de Lotman y otros autores) son de principios de los años sesenta. En 1969 Bachtín es rehabilitado oficialmente y en los setenta su obra empieza a ser publicada parcialmente. La Escuela de Tartu y la Universidad de Moscú son dos centros que retoman activamente el estudio de la obra de Bachtín. (Mancuso, 2005: p. 117)

Entre las condiciones de producción del pensamiento de Lotman no desconocemos las otras articulaciones con la tradición formalista y checa, así como, en los últimos años, el deslizamiento a los nuevos paradigmas de las ciencias, cuestiones que en algún momento hemos tratado de esclarecer (Arán-Barei, 2002). Pero la impronta bajtiniana en la obra de Lotman es algo más que coincidencias históricas o préstamos intertextuales. Ambas escrituras se resisten a ser explicadas en términos de evolución o de continuidad la una de la otra, sino que establecen una corespondencia en cuanto a la búsqueda de proyectos científicos transdisciplinares, holísticos, que permitieran pensar la obra artística en un medio sígnico osmótico, buscando las formas de esos pasajes. Son también la expresión de una resistencia intelectual a los determinismos mecanicistas y a las dialécticas teleológicas para explicar los productos culturales y los procesos históricos. Creo que la gran lección que nos han dejado es que las ciencias humanas construyen sus objetos de estudio en un imaginario abierto y pleno de incertidumbres acerca del orden de lo real. 


\section{Hombre y Cultura}

Los epígrafes que hemos seleccionado nos enfrentan con las dificultades y también con las oportunidades de construir un vínculo dialógico entre ambos pensadores que inician en el s. XX, con su obra, dos grandes paradigmas epistemológicos para dar cuenta del problema del lenguaje y de la cultura en su conjunto y de la función del arte en la trama cultural. En su enfoque intrínsecamente diverso, ambos convergen en una cuestión central: sentar las bases fundamentales del proceso de semiosis ilimitada y contradictoria que gobierna la cultura y desplegarla en direcciones sincrónicas y diacrónicas como variaciones de la memoria colectiva. No obstante, si hay vínculo dialógico sobre un campo común de problemas, no es un diálogo cordial y ameno, sino una tensa relación con desacuerdos y fricciones a partir de dos lógicas diferentes que sostienen, aún hoy, la producción intelectual en las ciencias humanas. Examinemos primero dos grandes nociones referidas a la dinámica cultural.

La idea que preside el constructo teórico de la semiosfera es la de un espacio políglota que tiende a semiotizar todo lo que cae en alguna de sus lenguas, a sabiendas del mundo no semiótico que queda fuera de las fronteras -siempre inestables y borrosas- de dicha semiosfera. Ese espacio volumétrico, atravesado también por fronteras internas, que Lotman describe casi como una galaxia cósmica, una guerra de mundos con velocidades diferentes que chocan, se superponen, se fragmentan o sufren procesos de explosión, es un medio modelizante plurilingüe pues afirma: "Nos hallamos inmersos en el espacio de la lengua" y una lengua es "código más historia" (1999: p. 16).

Cabe destacar que el diálogo bipolar es constante dentro de la semiosfera. Este diálogo bipolar (continuo/discreto; simetría/asimetría; semejanza/diferencia, etc.) otorga a la estructura en su conjunto su cualidad isomorfa bihemisférica con el cerebro humano. En tanto abstracción, este isomorfismo revelaría que, en todos los niveles y unidades de la semiosfera ("desde el nivel molecular genético hasta los más complejos procesos informacionales”, 1991: p. 22), se es, a la vez, todo y parte de una estructura mayor y de otra que a su vez la contiene, lo que, repetido al infinito, revelaría la misma estructura fractal de la naturaleza:

Puesto que todos los niveles de la semiosfera -desde la persona del hombre o del texto aislado

hasta las unidades semióticas globales- representan semiosferas como si puestas una dentro de la otra, cada una de ellas es, a la vez, tanto un participante del diálogo (el todo de la semiosfera), cada una manifiesta la propiedad de ser derecha o ser izquierda y encierra en un nivel más bajo estructuras derechas e izquierdas. (Lotman, 1991: p. 21)

Toda la energía del sistema en cualquiera de sus niveles tiende a un permanente objetivo que es la producción y acumulación del conocimiento y la disputa social e histórica para controlarlo (Lotman, 2001: p. 28). La cultura es un mecanismo autosuficiente, el "Logos que crece por sí mismo" como le gustaba decir citando a Heráclito de Efeso.

Bajtín, que también ha pensado la cultura como un medio lingüístico altamente semiotizado dirá que "en cada signo ideológico se cruzan los acentos de orientaciones diversas. El signo llega a ser la arena de la lucha de clases" (Voloshinov, 1992: p. 49, cursiva en el texto) puesto que el proceso de generación lingüística se expresa socialmente como un discurso multiacentuado y dialógico que no existe en la abstracción del sistema de la lengua. Dará un concepto de cultura que derriba la idea de una espacialidad orgánica compartimentada, de un adentro o afuera, o de un 
todo homogéneo intemporal, para quedarse con la cultura como construcción de sentido del hacer humano:

(...) no se debe representar la esfera de la cultura como un cierto todo espacial que tiene fronteras y también un territorio interno. La esfera de la cultura no posee ese territorio: está ubicada sobre fronteras que pasan por todas partes, a través de cada momento suyo, y la unidad sistemática de la cultura se extiende a los átomos de la vida cultural, reflejándose como un sol en cada una de sus partes. Todo acto cultural vive esencialmente sobre fronteras: en esto radica su seriedad y significación. Abstraído de éstas, pierde el terreno, se hace vacío, arrogante, degenera y muere. En este sentido podemos hablar de la sistematicidad concreta de cada fenómeno de la cultura, de cada acto cultural aislado, y de su participación autónoma y autonomía participante. Sólo en esta sistematicidad concreta, o sea en su situación y orientación directas en la unidad de la cultura, el fenómeno deja de ser simplemente un hecho real, desnudo, adquiere validez y sentido y deviene como una mónada que refleja en sí todo y se refleja en todo. (Bajtín, 1986: pp. 30-31)

Para Bajtín entonces, el medio cultural registra, a través de la palabra en acto, la dinámica por la imposición ideológica del sentido, si entendemos por ideología el efecto de verdad que crea una posición enunciativa ("evaluación social del enunciado”) que se arroga la totalidad; para Lotman en cambio, la lucha es por el control de la información, generación de conocimiento, modelización del mundo que permite intervenir en la realidad material.

La lucha por la información así entendida es la síntesis de la historia de la cultura, tanto de su construcción, como de su apropiación o destrucción. Puesto que la información es poder y control sobre el sistema, las luchas y conflictos, históricos, políticos, sociales o de clase han sido luchas por el monopolio y control de las múltiples y variadas formas o lenguajes en que la interacción semiótica se traduce en el incremento del conocimiento. Los grupos luchan por el monopolio de la información utilizando textos y códigos, de diversas clases y diversos grupos sociales, las lenguas "secretas" profesionales, religiosas, científicas, artísticas. Toda cultura se recorta sobre el fondo de aquello que define como Naturaleza o No cultura y desde el modelo histórico que produce, ejercita sus políticas sobre los individuos, las prácticas y las instituciones, tanto hacia el interior como hacia el exterior del propio colectivo.

De este modo la cultura, que para Bajtín es resultado histórico de fuerzas sociales y políticas, de una antagónica moral social que actúa enmascarada discursivamente, para Lotman se produce como necesidad de funcionamiento del propio sistema que se automodeliza. El ethos antropológico bajtiniano es desplazado hacia una antropología de la cognición. Lo cual nos coloca en otra intersección productiva de la semiosfera, la noción de texto y la espinosa cuestión del sujeto cultural.

\section{El texto como objeto transdisciplinar}

En un artículo escrito en 1981 Lotman destaca el considerable aumento del uso del término "texto" en tratados científicos y la consiguiente pérdida de la monosemia de dicha noción, lo cual "señala la actualidad de un problema, indica un dominio en el que nacen nuevas ideas" (1993: p. 117). De tal modo, insistirá en que la noción de texto es un concepto fundamental en ciencias humanas y tratará reiteradamente (en casi toda su obra), de precisar el alcance de dicha categoría en su edificio teórico. 
En términos muy generales podríamos señalar la noción de texto como un dispositivo cuasi inteligente, programado e interactivo, así como la noción de pluricodificación del texto y su vínculo con los códigos de la cultura. El texto sería el objeto primario de estudio, un sistema finito, al que ingresan diferentes códigos y lenguajes en múltiples combinaciones, formando una unidad textual heterogénea y dinámica, cerrada desde el punto de vista formal, pero abierta en cuanto a los códigos de los lenguajes que la conforman. Si se quiere entender la movilidad de la cultura se deberán estudiar los textos y el uso que éstos hacen de los sistemas modelizantes. El texto ocuparía el lugar del signo como unidad cultural que "teje" la interacción de sistemas semióticos mediante una variada tipología de textos, con diferentes grados de organización, con exclusión o combinación de lenguajes.

No se puede menos que recordar a Bajtín, quien, hablando de este tema, se había manifestado críticamente por una noción de texto verbal que tiene dos polos, el repetible, codificado por la lengua y el que ejercita una transformación semántica. En el ensayo "El problema del texto en la lingüística, la filología y otras ciencias humanas. Ensayo de análisis filosófico" plantea con claridad el proyecto transdisciplinar cuya "realidad primaria" sea el texto entendido como totalidad única e irrepetible desde el punto de vista semántico, ideológico e histórico, al que llamará "enunciado". Por ello, en clara referencia crítica apunta diferentes tendencias en el estudio de los textos que lo "cosifican" es decir, le quitan su cualidad específica humana que es la de ser "textos con voz". Nos parece leer una alusión a las investigaciones de Lotman cuando dice telegráficamente:

La cibernética, la teoría de la información, la estadística y el problema del texto. El problema de la cosificación del texto. Los límites de esta cosificación. (1982: p. 298)

El imaginario (y por lo tanto el metalenguaje) de Bajtín "humaniza" los textos, los refiere como "textos con voz" o textos "polifónicos" porque, en definitiva, son resultante de una conciencia intersubjetiva. La conciencia articula el sujeto con lo real y se produce por interacción sígnica con el medio externo y con las palabras ajenas; se organiza como un signo de frontera ideológica entre yo-tú, interno-externo. Pero, fundamentalmente, es el lugar de la esfera moral que impulsa el acto y la responsabilidad del sujeto históricamente situado. Por eso el sujeto no puede ser concebido como una abstracción, cartesianamente, sino como una totalidad concreta en toda su dimensión ontológica:

La unicidad singular no puede ser concebida, sino que tan sólo puede ser vivida

participativamente. Toda la razón teórica no es sino un momento de la razón práctica, es

decir, de la razón que viene de la orientación moral de un sujeto en el acontecimiento singu-

lar de ser. (1997: p. 20)

Es importante señalar que los textos que Lotman privilegia para el estudio semiótico son los que cumplen una función activa en el mecanismo de la cultura, no son meros transmisores de significados, sino generadores de un modelo de mundo y se organizan en tanto "sistemas": los rituales, las mitologías, las religiones, los juegos y, muy especialmente, los textos artísticos (verbales y no verbales) a los que dedica la mayor parte de sus estudios. En estos sistemas modelizantes secundarios, los objetos textuales se comportan como un "dispositivo", unidad con estructuras muy variadas y a menudo internamente contradictorias, dotado de principios de autoorganización, que cumple ciertas funciones. Se notará inmediatamente en la extrapolación de tal metalenguaje la impronta de teorías de sistemas de información y sistemas cibernéticos tal como hará, años después, Umberto Eco.

Pero este dispositivo, es un "dispositivo pensante" (1993: p. 119) que no funciona solo. Para que un texto "trabaje" debe aceptar la inclusión de otro texto, otro mecanismo inteligente, ya sea en forma de lector, de investigador, de contexto 
cultural. Como ocurre en la teoría de Peirce, la noción del interpretante que es connatural al signo, incorpora la noción de objeto dinámico y la producción de la semiosis. Muy cerca de Peirce quien sostenía que "el hombre es un signo", Lotman propone considerar el texto como una "persona semiótica" o "conciencia semiótica" que aunque presenta complejidades en cuanto a su acepción, repone la idea de un mecanismo codificante dotado de autonomía, con duración temporal, con memoria, y una individualidad, cuestión que al tiempo que dificulta el trato lo hace intelectualmente fructífero. El texto trabaja siempre cuando se conecta con otro texto, otra conciencia semiótica que interactúa de muy diferentes formas, que puede ser o no homogénea con el texto y que puede "traducir" dicho texto.

Es preciso señalar aquí dos cuestiones: la una, que Lotman retoma la idea del dialogismo bajtiniano, la necesidad del interlocutor, de la otra conciencia para que un texto funcione semióticamente porque "El texto como generador del sentido, como dispositivo pensante, necesita, para ser puesto en acción, de un interlocutor" (1993: p. 124) y ese mecanismo multilingüe sería la fuerza impulsora de la transformación cultural y definiría el objeto disciplinar de las ciencias sociales y humanas que Lotman reformulará como semiótica de la cultura. Pero, mientras la situación de respuesta es dialógica en Bajtín (los llamará "textos con voz") en la medida en que es una instancia sociopersonal, es sistémica en Lotman. El funcionamiento de los textos no está analizado por motivos de lucha de clases, o por motivos ideológicos, políticos, económicos, sino desde la tipología de las culturas que reinterpreta la estructura inmanente del texto original, según su propia capacidad de traducir los lenguajes.

La conciencia que entra al texto primario también sufre transformaciones que son de diversa índole, según la información que el texto vehiculiza, pero que siempre incrementa el conocimiento del interlocutor. Esta noción del "texto en el texto" es una ley de la dinámica cultural cuyo mecanismo es homeomorfo con procedimientos de la retórica textual por lo que el texto en su microestructura y funcionamiento es algo así como la célula madre (la unidad sígnica), que explica el funcionamiento de la cultura en su totalidad y de allí que toda la cultura pueda ser leída como un vastísimo texto.

Es notable que ambos investigadores reconozcan el texto como objeto transdisciplinar primario y como la unidad significante del tejido cultural. La gran diferencia, simplificadamente, es que en tanto Bajtín trata de recuperar la conciencia activa del hombre social e histórico que se expresa en los textos, Lotman se interesa por su funcionalidad en el interior de un sistema dinámico que hoy se asemejaría a lo que llamamos un "hipertexto", con multiplicidad de textos in-teractivos que las tecnologías mediáticas han vuelto tangibles.

Lo que se pone en discusión entonces es la dimensión intersubjetiva y la misma noción de sujeto cultural. Lotman describe el texto como mecanismo semiótico modelizante; Bajtín como posición enunciativa particular, como conciencia en acto y de allí que prefiera el término de "enunciado", que es lo único e irrepetible. No es poco, sin embargo, la coincidencia en reconocer que las ciencias sociales y humanas nunca acceden a una realidad que no esté mediada por textos y que los textos son una red sincrónica y diacrónica simultáneamente, al ser portadores de memoria.

Y éste es otro arduo problema para analizar que se liga a procesos de permanencia y cambio culturales y al concepto de Historia como memoria. 


\section{Memoria y cambio histórico}

En Bajtín el concepto de memoria está unido a su visión de la vida concreta de la palabra y de las relaciones dialógicas que ella establece a través del tiempo. Siendo el hablante un hombre social, la historia del devenir de la palabra es en buena medida la historia del hombre. La memoria compleja y conflictiva de la cultura se aloja en la palabra, en sus usos y en sus sentidos colectivos que, como ya vimos, son siempre ideológicos y múltiples. Por eso las palabras no olvidan su origen: de clase, de época, de géneros discursivos, del cauce de la vida y de la esfera de actividad en que fueron creadas, así como de las fuerzas que unifican o dispersan la vida del lenguaje:

(...) Todas las palabras tienen el aroma de una profesión, de un género, de una corriente, de un partido, de una cierta obra, de una persona, de una generación, de una edad, de un día, de una hora. Cada palabra tiene el aroma del contexto y de los contextos en que ha vivido intensamente su vida desde el punto de vista social; todas las palabras y las formas están pobladas de intenciones (...). L p. en la novela, TEN, 1989: pp. 106-111

Por eso pensamos que la expresión "arcaísmo vivo", que Bajtín aplica a los géneros literarios podría extenderse a toda la memoria cultural, representada por las entonaciones y acentuaciones del lenguaje verbal en constante renovación:

(...) El género es siempre el mismo y otro simultáneamente, siempre es viejo y nuevo, renace y se renueva en cada nueva etapa del desarrollo literario y en cada obra individual de un género determinado. En ello consiste la vida del género. (...) El género vive en el presente, pero siempre recuerda su pasado, sus inicios, es representante de la memoria creativa en el proceso del desarrollo literario y por eso es capaz de asegurar la unidad y continuidad de ese desarrollo. PPD, 1993: pp. 150-51

Es decir que palabra, memoria e Historia se anudan irremisiblemente y aunque la Historia, el Gran Tiempo como lo llamaba Bajtín, es un horizonte abierto, no hay sentido que se pierda y todo sentido se recupera y transforma, como reza el epígrafe que apuntamos, siempre lo hace en una dirección que intuimos como de perfeccionamiento moral y de resistencia al pensamiento hegemónico.

En Lotman, el tema es más complejo porque la memoria forma parte de la estructura de un sistema invariante que transmite información y crea programas de comportamiento. De allí que la primera definición sea la de una memoria no hereditaria y en consecuencia, sometida a diferentes mecanismos de completamiento o de destrucción total o parcial. La cultura se piensa como un lugar en el que se integra la información que se recibe del exterior -información nueva- con la que estaba almacenada. Esta información le permite a la cultura reconocer y dar sentido a lo nuevo o reinterpretar lo viejo. La memoria por lo tanto, no sólo retiene o evoca, sino que mediante una serie de operaciones puede olvidar el pasado, redistribuir los "hechos que han de ser recordados" y crear nuevos contenidos.

El pensamiento lotmaniano insiste en reflexionar acerca del trabajo de la memoria porque ella permite representar retrospectivamente el proceso de cambio, ya sea que éste se realice por continuidad (previsibilidad) o por explosión, por cambio brusco o violento de los sistemas culturales (imprevisibilidad). Los dos movimientos implican posibilidades de cambio -no hay culturas estáticas, sino en mayor o menor medida, dinámicas-, sólo que el primero es gradual y el otro, repentino. Ambos no se excluyen y hasta son interdependientes dentro de las esferas de las prácticas culturales de una semiosfera.

Interesa destacar que en la última época el "testamento de Lotman" (Segre, 1997: p. 87) muestra que la Historia es no sólo lo dicho como historiografía, sino 
también lo que no se ha dicho pero puede llegar a decirse desde la generación de nuevos textos que recuperen el haz de variables equiprobables que rodean al acontecimiento efectivamente producido. Memoria histórica no solamente factual, no solamente como recuerdo o depósito, sino como construcción en el presente de lo que importa recuperar. Cada época construye su memoria con vistas al futuro. Es ese presentimiento del futuro que consignamos en el epígrafe y que lo aproxima a Bajtín sin confundirlo.

El movimiento intenso de la memoria en la semiosfera, la tendencia por una parte, a la simetría y el equilibrio, propios también del mundo natural y por la otra, la necesidad de crear textos nuevos que producen desequilibrios en los sistemas (y nuevo conocimiento) es lo propio de la ciencia y del arte, aunque por vías diferentes. En este caso, Lotman encuentra en el arte -de allí sus estudios sobre cine, pintura, teatro, literatura- el espacio experimental ideal para examinar el funcionamiento de tipos de lenguaje no discretos:

El arte representa un generador magníficamente organizado de lenguajes de un tipo particu-

lar, los cuales prestan a la humanidad un servicio insustituible, al abarcar uno de los aspectos más complejos y aun no del todo aclarados del conocimiento humano. (1978: p. 13)

La noción de texto artístico en el mecanismo de la cultura, para Bajtín es una refracción vital, una cronotopía, el modo en que el arte, a través de la conciencia creadora (interna a la obra y bivocal), asimila e interpreta las formas espaciales y temporales de la propia realidad. La obra de arte vive y tiene significación artística en una interdependencia tensa y activa con la realidad, identificada y valorada a través de la acción. Lo reelaborado, en virtud de esa tensión valorativa, no puede ser nunca la materia caótica, desorganizada y neutra, sino la realidad tal como fue prevista en los otros dominios de la cultura, de tal manera que la vida ("el flujo semántico de la vida”, Bajtín, 1989: p. 31) ingrese en la obra.

Para Lotman el arte funciona como un mecanismo de intelección poco conocido, vinculado con el sueño, el error, el azar; está situado en la frontera entre transmisión de información conocida y producción de nueva información. Tanto para Bajtín como para Lotman la obra artística es una modelización del mundo, que el primero define como "arquitectónica", en vínculo con lo estético y lo político y el otro como sistema de modelización secundario cuya estructura cumple función primordial en el tejido cultural.

Si la Historia "no conoce repeticiones, sino que ama las rutas nuevas, imprevisibles" (Lotman, 1999: p. 229), el arte es un lugar privilegiado donde la memoria cultural sirve para crear un espacio de libertad explosiva es decir, creativa, ya que ambas nociones son equivalentes para Lotman:

Y así el arte alarga el espacio de lo imprevisible, el espacio de la información y, al mismo

tiempo, crea un mundo convencional que experimenta este espacio y proclama su victoria sobre él. (1999: p. 168)

Pensamos que en lo que ambos investigadores han acordado por caminos diferentes es que el arte realiza en su bondad incesante la casi imposible tarea de transformar lo real de la cultura en un potencial excedente de sentido simbólico de consecuencias impredecibles.

\section{Las dos fundaciones y la cultura contemporánea}

$\mathrm{Al}$ inicio de nuestra exposición sostuvimos que los dos proyectos teóricos que hemos puesto en intersección se consideran, 
en una operación de reconocimiento (Verón, 1998), como discursos "de fundación" epistemológica: Bajtín funda la teoría de la discursividad social y Lotman una semiótica cognitiva que intenta recuperar el vínculo naturaleza-cultura. Los supuestos de la propuesta sociolingüística de Bajtín son leídos por Lotman en otro marco teórico, fundamentalmente de la cibernética y la teoría de la información; los primeros se ejercitan en la condiciones pre y postrevolucionarias inmediatas y los segundos en una posición de resistencia a la vulgata oficial, sin tomar aquí en consideración los exilios biográficos de cada uno.

Los textos de Bajtín estaban comprometidos en la fundación ética de la acción colectiva y en el modo como el tejido social libra sus batallas de cultura oficial y contracultura. Su perspectiva es fenomenológica y su metodología se aproxima a lo que hoy denominamos un trabajo de campo como punto de partida para toda especulación cognoscitiva. Sus textos son una respuesta al problema de la acción personal en momentos en que como intelectual se sentía obligado a una participación responsable y a una comprensión del "yo para otro" y el "otro para mî". Su matriz es filosófica e histórica y el examen de todas las disciplinas en construcción, en especial la lingüística, pasa por esa matriz, en el quiebre de las certidumbres positivistas que marcan el pasaje del s. XIX al s. XX, que Bajtín traslada hacia un humanismo con base materialista.

Estos textos son recibidos por Lotman dentro de un proyecto semiótico elaborado en un lugar de frontera geográfica y política y para el que las fronteras externas e internas a la cultura se vuelven objeto temático y categoría analítica. Su discurso funda una ciencia de los sistemas de signos desde una perspectiva funcional y pragmática. Su matriz es comunicacional, lógica y matemática, buscando una ciencia unificada que pueda elaborar modelos de cognición que lleguen a emular, nunca a suplantar, el modelo del cerebro de la especie humana. Esa matriz teórica es deudora de los grandes adelantos científicos y tecnológicos de la segunda mitad del s. XX que él transforma en una variante de la antropología estructural.

Creo que ambos paradigmas deben ser recuperados productivamente en nuestras condiciones actuales, en un estado del arte finisecular definido como posthistórico, un estado de la cultura definida como postmoderna y un estado de la geopolítica neutralmente definida en términos de globalización. Estas denominaciones, más allá del soporte ideológico que conllevan, transmiten el impacto de cambios explosivos y la percepción de una cultura en acelerada mutación, con nuevas fronteras étnicas, sexuales, morales, biológicas y nuevos sujetos culturales. El punto de inflexión histórica que marcó la caída del bloque soviético dio lugar a cambios en el mapa sociopolítico, a nuevas hegemonías y a una cultura con caracteres estructurales de enormes avances técnicos, científicos y económicos, protagonismos de minorías, flujos migratorios, superposición del tiempo-espacio real y virtual. Los múltiples estudios sobre la cultura enfatizan el llamado multiculturalismo, las nuevas identidades sociales y correlativamente, la interdisciplina y el abandono de la ortodoxia metodológica como modo de respuesta a la creciente complejidad.

Todo esto hace necesario recuperar en este nuevo contexto algunas advertencias de los paradigmas fundacionales analizados, los valores de ética y humanidad que responden por el "otro", por el respeto de su memoria y por la distribución de la riqueza, así como los nuevos lenguajes informáticos y sus retóricas de verosimilización de lo real social, que se traducen en una impresionante concentración de poder y de saber en una semiosfera massmediatizada. En estas nuevas condicio- 
nes, el diálogo entre culturas y la traducción son asimétricos y conflictivos y el problema de la comunicación y accesibilidad entre culturas y sujetos culturales diseña un mapa de tensiones y catástrofes. Nos gustaría pensar que en el arte contemporáneo se esconden los presentimientos de las rutas posibles, del complejo de potencialidades que deparan la libertad y la invención en momentos de "aumento de informatividad de todo el sistema" (Lotman, 1993: p. 28) y que el arte sigue resistiendo a la monoglosia, a la imposición de una lengua por otra, a la idea de la transparencia comunicativa, al rescate de la memoria, al puro valor de mercancía.

$\mathrm{Al}$ parecer, el intelectual ha abandonado definitivamente los grandes relatos (y aunque con final incierto, en los de Bajtín y Lotman hay coincidencia en las metas lejanas) para explicar la trama total de las determinaciones culturales, en un creciente contexto de pérdidas de certezas y de utopías diversas. Habrá que pensar quizás no en esquemas científicos o históricos omnicomprensivos, sino en relatos teóricos particularizados y minimalistas que puedan dar cuenta de trayectos acotados, creando nuevos objetos de estudio y quizás nuevas lógicas o retóricas discursivas para modelos epistémicos (con vocación transdisciplinar, interpretativa y crítica) que se apliquen al pensamiento situado de variables culturales, a los imaginarios sociales, a nuevos contextos y prácticas en una sociedad de trama fragmentada y a nuevas automodelizaciones culturales que imponen íconos y consumos masivos de identificación.

La filiación antropológica de los modelos de Bajtín y de Lotman nos invitan a confiar en su traslado productivo para describir sociedades como las nuestras, latinoamericanas, en acelerados procesos de transculturación y de diferenciación, con topografías de desigualdad en progreso, con memorias locales amenazadas. Sin duda las teorías de esos dos formidables pensadores contienen grandes claves y herramientas conceptuales para desplegar en diálogo con nuestra vivencia cotidiana del debilitamiento del sentido de pertenencia y grupalidad. Sus paradigmas son intrínsecamente dialécticos, abiertos, no clausurados y por eso siguen alimentando un potencial teórico dialógico que merece ser revisado.

\footnotetext{
Nota

${ }^{1}$ Conceptos de este trabajo son recogidos en una conferencia leída en San Pablo, en ocasión del I Encontro Internacional para o estudo da Semiosfera, que tuvo lugar en el Centro Universitário Belas Artes, del 22 al 27 de agosto de 2005.
}

\section{Bibliografía específica}

BajTín, M.: (1989) "El problema del contenido, del material y de la forma en la creación artística verbal” en Teoría y estética de la novela, Taurus, Madrid.

(1982) "El problema del texto en la lingüística, la filología y otras ciencias humanas. Ensayo de análisis filosófico" en Estética de la creación verbal, Siglo XXI, Méjico, pp.294-323.

(1989) "La palabra en la novela" en Teoría y estética de la novela, Taurus, Madrid. 
(1993) Problemas de la poética de Dostoievsky, F.C.E., México.

(1997) Hacia una filosofía del acto ético. De los borradores y otros escritos, Anthropos, Barcelona-Puerto Rico.

Lotman, I.: (1978) "La estructura del texto artístico" en Colec. Fundamentos No 58, Istmo, Madrid.

(1991) “Acerca de la semiosfera" en Criterios № 30, julio-dic. 1991, La Habana, pp. 3-22.

(1993) "El texto en el texto" en Criterios No especial UNAM-Casa de las Américas, julio, pp. 117-132.

(1994) "Cerebro-Texto-Cultura-Inteligencia artificial" en Criterios No 31, enero-junio 1994, La Habana, pp. 207-221.

(1994) "La memoria a la luz de la culturología" en Criterios No 31, enero-junio 1994, La Habana, pp. 223-228.

(2001) "Introduzione" a Lotman-Uspenskij, Tipologia della cultura. Edic. a c. di Remo Faccani e Marzio Marzaduri. Ediz. Tascabile Bompiani, Milano, pp. 25-35.

(1999) Cultura y explosión, Gedisa, Barcelona.

Voloshinov, V.; Bajtín, M.: (1992) El marxismo y la filosofía del lenguaje, Alianza, Madrid.

\section{Bibliografía complementaria}

ArÁn P. y BAReI, S.: (2002) Texto / Memoria / Cultura. El pensamiento de Iuri Lotean, Univ. Nac. de Córdoba, Córdoba, Argentina.

CÁCERES, M.: (1997) En la esfera semiótica lotmaniana. Estudios en honor de Iuri Mijailovich Lotman, Colecc. Eutopías, Episteme, Valencia, España. Mancuso, H.: (2005) La palabra viva. Teoría verbaly discursiva de Michail M. Bachtín, Paidós, Buenos Aires.

Verón, E.: (1998) La semiosis social, Gedisa, Barcelona. 